required in step 3 on page 136, and again its sourcing from ArcGIS Online is not mentioned.

Some of the instructional steps within the scenarios require the provision of more information if users are to complete each scenario. As with most GIS tutorials, individuals who take this tutorial by themselves or as a group should expect to devote a significant amount of time to working through each scenario.

This book lends itself best to a classroom setting where students can ask questions of their instructor, or fellow students who have been through the workbook scenarios. Individuals who take this tutorial solo, and without having a basic understanding of lidar and how it functions, could have some difficulty getting through it. Taking this tutorial in a classroom setting where students are divided into small groups would be to the individuals' advantage vs. taking it on their own.
It is noted in the Acknowledgements section that the workbook was created with contributions from students and teachers from the Geospatial Semester held at James Madison University, and that high school students who participated in the Geospatial Semester helped test each module in order to provide feedback.

All-in-all, this is a useful tutorial workbook for individuals who already have a basic knowledge of lidar and possess basic GIS skills. Although some of the instructional steps for following the scenarios would benefit from being a bit more detailed, the authors did well in creating real-world scenarios that represent a variety of disciplines, and the workbook enables users with GIS experience to expand their skill set (utilizing lidar) to solve problems that face the environment. I would recommend this workbook to university faculty (from select academic disciplines) with the suggestion that they integrate the workbook as part of an Introduction to Lidar course or Remote Sensing Technology course.

\title{
CARTOGRAPHIC JAPAN: A HISTORY IN MAPS
}

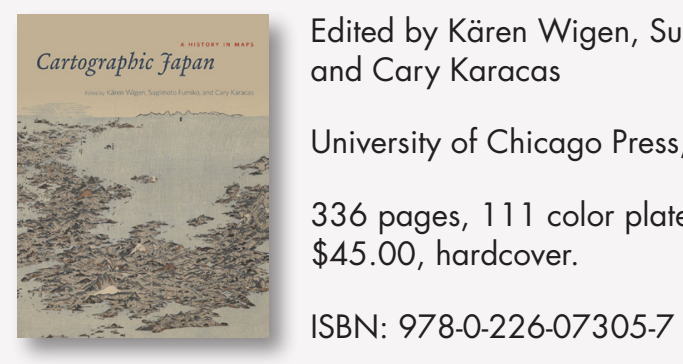

Review by: Mark Denil

For the western observer, Japan is an enigmatic land. It is both like and unlike, familiar and alien, clear and clouded, straightforward and not-quite; and it is all these things all at the same time. As Lafcadio Hearn wrote over a century ago, recounting the words of a close Japanese friend: "When you find, in four or five years more, that you cannot understand the Japanese at all, then you will begin to know something about them" (Hern 1904, 5).

Cartographic Japan: A History in Maps, from the University of Chicago Press, is expressly intended to open a window for the non-Japanese reader on a sweeping landscape of Japanese cartographic artifacts, history, and scholarship. The fifty-two short essays by forty-eight authors, "each focused on one or two maps related to the contributor's specialty" (3), are organized in four roughly chronological Parts and then further into thematic sub-groups. Although there are occasional references from one to another, for the most part each essay stands alone.

Japanese cartography, like much of Japanese culture and technology, developed in a cyclic manner. Foreign influences would, from time to time, wash over native practice; sometimes swamping local traditions, sometimes being absorbed and assimilated, and sometimes creating new streams of tradition alongside those already existing. In each case, that which remained and flourished would itself become Japanese. Cartographic Japan examines a large number of maps representing developing cartographic practices, and offers commentary on how many of these streams of infiltrations, minglings, and adaptations played out over the years.

Prevailing historical, political, and social conditions always frame the environment for cartographic practice, production, and products, and in Cartographic Japan the three most recent Japanese historical periods are used to divide the essays into four main Parts. These are titled: 
I. Visualizing the Realm: Sixteenth to Eighteenth Centuries

\section{Mapping for the Market}

\section{Modern Maps for Imperial Japan}

IV. Still under Construction: Cartography and Technology since 1945.

Supporting the essays is a general Introduction, plus individual Introductions to each of the four Parts, as well as a brief Epilogue wrapping up the historical narrative with a look at a contemporary map. The standard sections: "Acknowledgments," "About the Authors," and an Index, are grouped at the end.

The first two Parts are overshadowed by Japan's long-standing feudal institutional structure, epitomized by the Tokugawa Shogunate and centered in Edo (since renamed Tokyo). The maps in these sections form the baseline for the overall survey, but this baseline is anything but static. Although often considered primarily a period of isolation, the Edo period was not one of stagnation. It was a period of practically unbroken peace: beginning about 1600 , in fewer than fifty years Japan was transformed from a tangle of warring clans into a peaceful and peace-loving state. There were troubles, especially in the far north and south, and peace was only preserved by an extraordinarily vigilant military feudalism, but it was also a time of general prosperity and cultural progress. Education was improved and extended, books were printed and circulated in large numbers, and art was cultivated; it was the two and a half centuries of Tokugawa peace that laid the groundwork for the new Japan that burst upon the world with the Meiji revolution (Gowen 1927, 247).

The earliest maps discussed are amongst the oldest existing maps of Japan. The sub-section "Japan in the World" explores the Japanese view of the place of Japan in the world: a view even then already reflecting aspects of the wider world's view of both itself and of Japan. Other sections in Parts I \& II present views of "Domestic Space," "Mapping the City," "Sacred Sites and Cosmic Visions," and "Travelscapes."

The transition of feudal Japan into the Imperial Japan of the Meiji Restoration and Renaissance is the unifying theme of Part III. Japan, in this period, began a wholesale importation of western technology and practice, diving into a veritable tsunami of learning, adopting, adapting, copying, and improving. In this dynamic time Japan leapt onto the world stage: exploding illusions, elbowing aside competitors, and slapping down challengers, as well as acquiring, and administering, colonies. This newly westernized Japan, however, was still Japan, and traditional threads remained present and discernible in the new-form tapestry.

The maps in Part III begin with early Japanese moves into modern nautical charting, as native map makers learned to use the tools of the circling and intruding foreign powers to counter their threats to the homelands. Going forward, other modernized approaches were mastered and adapted to cadastral records and to disaster relief, while increasingly sophisticated maps were used to analyze, propose, and implement increasingly sophisticated solutions in infrastructural and urban administration and planning both at home and in the growing Empire. By the 1930s and 1940s, Japanese cartography, like other aspects of Japanese technology, was in the vanguard of the world standard, and this up-to-dateness included the production of map products targeted at the engineering of consent; at home, in the colonies, and abroad.

While the Empire came to a sticky end, Japan, and Japanese mapping, went, and continues to go, on.

The essays in part IV offer precious perspectives on an era of rapid change. While interested readers can readily turn elsewhere for studies of party politics, social movements, or international relations, the contributors to this final part of Cartographic Japan have elected to revisit some of the chief themes that have preoccupied Japan's mapmakers since the Edo era: urban life, people on the move, sacred landscapes, and hazardous events. Along the way, their contributions illuminate the broad arc of postwar Japanese history, from recovery to growth to newfound vulnerabilities. (188)

Just as the Shogunate formed the background for the first two Parts of Cartographic Japan, the beginning of Part IV is dominated by the 1945 foreign invasion and occupation. US tactical maps, for example, illustrate the evolution of battlefield aims from interdiction of Japanese war-making capacity towards plain and simple mass firebombing, and a 
post-surrender map of central Tokyo makes visible the reality of a hostile occupying army's dominating boot-print. A map setting out one of the competing legal claims for control of Mount Fuji, at issue only as a result of invader-enforced politico-religious reforms, highlights the persuasive power of a map in arguing a wholly novel position before a wholly new judicial body on a question that would never previously have arisen. Effects of the defeat and occupation trauma still echo today, long past the revival of Japanese industry brought on by the Korean War, the subsequent end of official US occupation, and the still-slowly-ongoing withdrawal of "friendly" occupation troops.

After dealing with these matters, however, the essays in Part IV move on to discuss the wealth of cartographic innovation being brought to bear on the issues of "urban life, people on the move, sacred landscapes, and hazardous events" (188) mentioned in the quotation above. These are some of the most interesting essays in the volume.

Physically, Cartographic Japan: A History in Maps is stur$\mathrm{dy}$, well bound, and very much the high quality book one expects from the University of Chicago Press. Listing for $\$ 45$, it is not unreasonably priced, and is a good value all around.

This is perhaps not a book one should expect to read straight through; the essays are short and succinct, but as a steady diet are perhaps a bit staccato for ideal digestion. There is, nonetheless, a tremendous wealth of information here, clearly coming from a great depth of expertise, and this reviewer has not found a single essay in the volume that was not engaging and worthwhile. The texts are aimed at non-Japanese readers, but a slightly more-thannodding familiarity with Japanese history and culture is a great help in getting the most out of the texts. Be advised that Cartographic Japan: A History in Maps is neither a primer on Japanese mapping nor on Japanese history.

This book's greatest shortcoming is in its small illustrations. Each map discussed is shown, often with an additional detail image and many times with English annotations, but almost all of the maps are so dramatically reduced in size that they are very difficult to read. The English annotations, too, are sometimes less than sophisticated in application, but that so many interesting maps are shown so small is very disappointing. That said, there are no poor illustrations in Cartographic Japan: it is just that one could wish for larger ones.

\section{REFERENCES}

Gowen, Herbert. 1927. An Outline History of Japan. New York: Appleton.

Hearn, Lafcadio. 1904. Japan: An Attempt at Interpretation. New York: Macmillan. 